\title{
O plano de ação para a criação do Estatuto da Cidadania do Mercosul
}

Aline Beltrame de Moura*

\section{UMA NOVA DIMENSÃO DO PROCESSO DE INTEGRAÇÃO REGIONAL DO MERCOSUL}

Um processo de integração regional pode implicar a construção de uma nova noção de cidadania, ligada ao fenômeno integracionista, que ultrapasse a tradição interna dos Estados e exija uma conceituação mais elástica ${ }^{1}$. Os esforços tomados em direção ao estabelecimento de uma democracia supranacional e de uma cidadania comunitária são certamente capazes de dar consistência a formas de convivência local e regional mais transparentes, participativas e solidárias. Baseadas na cooperação, no respeito à diversidade local e na harmonização dos interesses comuns, a cidadania comunitária reduz as diferenças, realiza formas de sinergia e favorece, assim, o reconhecimento dos direitos humanos e a criação de outros direitos de participação, econômicos e sociais para os cidadãos latinoamericanos no Mercosul². $^{2}$.

Considerando o complicado percurso do reconhecimento da dimensão social, a ausência desta perspectiva na fase inicial da integração e as dificuldades acerca da implementação das recentes novidades no âmbito institucional e normativo, não surpreende que o Mercosul apresente, atualmente, uma insuficiência de regras que poderiam servir de fundamento a uma cidadania comum para os indivíduos dos Estados-partes e que se aproxime, de qualquer maneira, daquela europeia. O que se tem observado é que, nos últimos anos, foram realizados progressos significativos no sentido de reconhecer novos direitos aos cidadãos dos Estados-partes através, principalmente, do direito derivado do Mercosul, isto é, da atividade realizada pelos órgãos executivos, nomeadamente o Conselho Mercosul Comum. A partir desta perspectiva, o debate em torno do instituto da cidadania torna-se inevitável em um processo de integração que, mesmo a longo prazo, mantém o objetivo de se tornar um mercado comum, de

* Doutora em Direito pela Università degli Studi di Milano. Professora da UFSC. 
enfrentar novos desafios e de repensar conceitos tradicionalmente ligados ao Estado-Nação.

O salto qualitativo na matéria de migração e circulação de pessoas dentro do espaço territorial do Mercosul ocorreu durante a XXIII Reunião do Conselho Mercado Comum entre os dias 5 e 6 de dezembro de $2002^{3}$ com a assinatura de Acordos sobre a Migração e a Residência dos cidadãos dos Estados-Partes do Mercosul. Diferentemente do que se possa imaginar, estes Acordos não preveem nenhum requisito ligado à situação socioeconômica ou laboral do migrante, a condição principal para ser beneficiário destes direitos é somente aquela de ser titular da nacionalidade de um dos Estados-Partes.

Os acordos sobre a Residência são relevantes na medida em que se compreende que o direito à residência, resultado direito da circulação do indivíduo, pode ser considerado um primeiro grau de pertença, e a cidadania, o passo subsequente. De fato, a partir da circulação e da residência - e através destas - torna-se possível instituir significativos direitos comuns que têm como futuros sujeitos beneficiários os nacionais de diversos países. Seria esta a base para um estatuto jurídico da cidadania do Mercosul.

Se analisarmos o exemplo paradigmático da União Europeia nota-se como, em um primeiro momento, a liberdade de circulação esteja concentrada, principalmente, nas liberdade de mercado comum com o simples escopo de facilitar a circulação dos trabalhadores. Originalmente, os direitos de cidadania nasceram, sobretudo, com a finalidade de completar o direito à liberdade de circulação no território europeu. Tão somente em um segundo momento é que os direitos derivantes do Acordo Schengen foram "comunitarizados" e as prerrogativas políticas conexas à cidadania europeia foram desenvolvidas ${ }^{4}$.

No Mercosul, ao invés, o desenvolvimento da liberdade de circulação de pessoas, em termos gerais, sempre foi observado levando em consideração uma tríplice perspectiva econômico-político-social e não apenas econômica. Em síntese, a circulação e a residência das pessoas ocorreram por meio de diferentes instrumentos jurídicos colocados em prática simultaneamente nas áreas da circulação dos trabalhadores, da redução dos controles nas fronteiras, do aperfeiçoamento de um quadro geral de regulamentação em matéria social e das facilitações em matéria migratória e de residência para os nacionais de qualquer Estado-Parte. Nesse sentido, a dimensão social não foi simplesmente considerada como um complemento da liberdade de circulação, inicialmente destinada apenas aos trabalhadores, mas como uma proteção da pessoa enquanto tal, ou seja, ligada a uma noção mais ampla de direitos fundamentais ${ }^{5}$. Prova disso são os citados Acordos sobre Migração e Residência, os quais disciplinam as situações jurídicas subjetivas que dizem respeito aos cidadãos em geral e não somente àqueles que exercem uma atividade laboral.

Na perspectiva de uma integração completa, que se ocupa não apenas da redução dos controles migratórios interregionais, mas também da proteção e 
da tutela dos direitos do indivíduo no campo laboral e social, percebe-se como no Mercosul esta atenção em direção à regulamentação de um estatuto jurídico vá além da mera autorização de atravessar as fronteiras estatais.

Certamente, o Mercosul constitui uma realidade, em termos de consolidação institucional e política, completamente diferente daquela europeia. A estrutura organizacional é intergovernamental, o direito derivado necessita de incorporação nos ordenamentos internos e o controle das fronteiras, muito embora as facilitações e uniformizações, ainda se verifica nos confins estatais. Diante desse cenário pouco transnacional, parece prematuro imaginar, num curto lapso temporal, o desenvolvimento de uma noção de cidadania comunitária, apesar de os recentes desenvolvimentos no tratamento da questão migratória façam emergir o conceito de livre circulação enquanto categoria chave para a problemática da cidadania ${ }^{6}$. Sob este ponto de vista, foram eliminados muitos fatores de vulnerabilidade, nomeadamente, a situação migratória irregular daqueles residentes em outro Estado-Parte e, de consequência, a sua melhor inserção na comunidade de acolhimento.

Além disso, apesar do persistente caráter intergovernamental, o Mercosul já se encontra hoje capaz de predispor intervenções regionais em áreas específicas, como a previdência social, o emprego e a saúde. O direito mercosulino, todavia, resta carente de disposições capazes de reconhecer, de modo claro e preciso, um direito dos cidadãos dos Estados-Partes de circularem livremente em todo o território enquanto um autêntico direito de cidadania ${ }^{7}$. Recorda-se que os Acordos sobre Residência preveem uma liberdade de circulação em sentido "bilateral", isto é, válida somente entre o Estado que emitiu a autorização de residência e aquele de origem do indivíduo, não se aplicando a todo o território do Mercosul. Por tais motivos, foi evidenciado que os Acordos parecem mais estabelecer um espaço de livre residência que uma verdadeira liberdade de circulação.

Sob tal perspectiva, a liberdade de circulação e residência das pessoas no Mercosul afasta-se da atual regulamentação vigente no contexto da integração europeia que se configura como uma liberdade que compõe o estatuto fundamental do cidadão europeu. Ademais, este direito é exercitado no chamado espaço de liberdade, segurança e justiça que implica a supressão, e não a mera facilitação, dos controles dos cidadãos europeus que atravessam as fronteiras internas. De fato, no Mercosul tal controle, muito embora flexível em comparação aquele realizado aos nacionais de terceiros países, é ainda presente aos nacionais originários de um dos Estados-Partes.

De qualquer modo, a necessidade de "preencher" de cidadania o Mercosul foi o argumento central do discurso do Presidente do Uruguai, Tabaré Vazquez, ao assumir a Presidência pro tempore do Conselho Mercado Comum no segundo semestre de 2005. Em particular, o Presidente salientou que o Mercosul não se decreta, mas se constrói, não se invoca, mas se convoca e que este não é um tema de poucos, mas de todos. Além disso, afirmou que "no hay integración económica 
sin integración social. No hay sociedad sin ciudadanía. Ha llegado el momento de comenzar a llenar de ciudadanía al Mercosur. ... Solo se conformará una identidad regional, coexistente con las identidades nacionales que hay que preservar y fortalecer, por cierto, si nuestros pueblos comienzan a reconoscerse como partes diversas de una única y dinámica unidad"8. A atenção política verso esta matéria é evidente e teve início, de modo concreto, nos debates promovidos pelas Cúpulas dos Chefes de Estado e de Governo para posteriormente ser objeto de estudos específicos nos grupos temáticos e nas reuniões especializadas do Mercosul.

De fato, como resultado da atividade de estudo e de pesquisa realizadas pelos órgãos mercosulinos, a Comissão dos Representantes Permanentes do Mercosul $^{9}$ publicou, em 2010, a Cartilha do Cidadão do Mercosul, isto é, uma consolidação normativa destinada aos nacionais dos Estados-Partes ${ }^{10}$. Como sugerido pelo próprio título, trata-se de um documento que reúne todas as normas vigentes emanadas pelos órgãos do Mercosul e que, de um modo ou de outro, dizem respeito à vida quotidiana do nacionais dos Países que o compõem, os quais são denominados pelo próprio documento como "cidadãos do Mercosul". O objetivo desta Cartilha é fornecer informações sobre os direitos e sobre as obrigações que derivam dos instrumentos aprovados no âmbito do processo de integração.

O conteúdo do Manual é estruturado em dez pontos, dentre os quais, citam-se: circulação de pessoas e de bens, trabalho e previdência social, educação, exercício de atividade econômica, cooperação consular, direitos humanos, integração cultural e aspectos de saúde pública. Ao final do documento, encontramse algumas Declarações dos Presidentes dos Estados-Partes e recomendações do Conselho Mercado Comum que estabelecem orientações políticas para orientar os órgãos do Mercosul e dos Estados-Partes nas suas relações com os cidadãos.

\section{O ESTATUTO DA CIDADANIA DO MERCOSUL}

Seguindo a diretriz estabelecida pela Cartilha, durante a XL Reunião do Conselho do Mercado Comum, ocorrida em Foz do Iguaçu no mês de dezembro de 2010, foi adotado o Estatuto da Cidadania do Mercosul, mediante a Decisão CMC n. 64/10 que entrou em vigor no mesmo momento da assinatura, com base na previsão do seu art. 8 que lhe concedeu a eficácia direta ${ }^{11}$.

$\mathrm{O}$ art. 1 especifica a natureza do ato como Plano de Ação para a criação progressiva de um Estatuto da Cidadania do Mercosul, sendo composto por um conjunto de direitos fundamentais e de benefícios para os cidadãos dos EstadosPartes. É uma iniciativa de grande importância tendo em vista que a Decisão expressamente prevê a adoção do conceito de "Cidadão do Mercosul" através da assinatura de um protocolo internacional anexo ao Tratado de Asunción até o ano de 2021, data do $30^{\circ}$ aniversário de criação do Mercosul ${ }^{12}$. 
Neste Plano de Ação, os Estados recordam a premência de o Mercosul implementar uma estratégia regional de desenvolvimento progressivo e de adotar um comportamento multidimensional em matéria de política, economia, comércio, educação, cultura, cooperação judiciária e de segurança. Afirmam, ainda, a necessidade do aprofundamento da dimensão social e cidadã do processo de integração. Com tal finalidade, os instrumentos já adotados no âmbito desta organização visam garantir à todos os cidadãos dos Estados-Partes e aos seus familiares o gozo dos mesmos direitos e das liberdades civis, sociais, culturais e econômicas, sem nenhuma discriminação em razão da nacionalidade.

Na realidade, é um documento que parece lançar perspectivas certamente promissoras quanto ao progressivo estabelecimento de um Estatuto da Cidadania do Mercosul. Apesar disso, solicita-se ainda uma ação para a sua concretização que, imprescindivelmente, deverá passar pela emanação de disposições claras e precisas $^{13}$. De qualquer modo, o estabelecimento, o mais breve possível, da noção de uma cidadania do Mercosul implicaria um avanço positivo e inédito para os direitos e as obrigações concernentes aos nacionais dos Estados-Partes ${ }^{14}$.

$\mathrm{O}$ art. 2 da Decisão prevê que o Estatuto da Cidadania do Mercosul seja integrado por direitos fundamentais e prerrogativas para os nacionais dos Estados-Partes. Como objetivos gerais são especificados a atuação de uma política de livre circulação de pessoas na região, a previsão de paridade de direitos e das liberdades civis, sociais, culturais e de iniciativa econômica de tais cidadãos e, ao mesmo tempo, de igualdade de condições para o acesso ao trabalho, à saúde e à educação.

Analisando, todavia, acuradamente o documento, depreende-se que estes objetivos não seriam nada mais que os direitos já previstos nos Acordos sobre a Residência. Em última análise, portanto, poderia ser dito que, em sentido amplo, o Estatuto do Cidadão do Mercosul já existe e se encontra em vigor desde 2009, data em que os citados Acordos entraram em vigor em todos os Estados-membros.

Certamente o Conselho Mercado Comum, durante a elaboração do Plano de Ação, tinha conhecimento que os Acordos sobre Residência já estavam em vigor e que estabeleciam tais direitos, mas eram igualmente conscientes das dificuldades em torná-los plenamente efetivos. Em razão disso, o art. 3 dispõe um elenco de ações que devem ser tomadas a fim de garantir a efetividade do Plano, dentre as quais salienta-se: 1) circulação das pessoas: facilitação do trânsito e da circulação no espaço do Mercosul, com a simplificação dos procedimentos de migração e da gradual harmonização dos documentos aduaneiros e migratórios; 2) Fronteiras: alargamento gradual das Áreas de Controle Integrado e revisão do Acordo de Recife; 3) Identificação: inserção da denominação "Mercosul" nas carteiras de identidade nacionais; 4) Documentação e cooperação consular: ampliação dos casos de dispensas da tradução e da legalização de documentos, alargamento dos mecanismos de proteção consular; 5) Trabalho e emprego: revisão da Declaração sócio-laboral do Mercosul, reforço da Comissão sócio-laboral, elaboração dos 
planos regionais em matéria de facilitação da circulação dos trabalhadores; 6) Previdência Social: integração dos bancos de dados sobre informação previdenciária e trabalho nos Estados-Partes; 7) Educação: simplificação dos procedimentos para a equivalência dos diplomas e consolidação de um espaço de mobilidade acadêmica; 8) Transporte: criação da "Carteira de Habilitação do Mercosul"; 9) Comunicação: redução do preço da tarifa da telefonia fixa e móvel entre os Países do Mercosul; 10) Defesa do Consumidor: criação de um Sistema Mercosul de Defesa do Consumidor; 11) Direitos Políticos: avaliação das condições para avançar progressivamente em direção ao reconhecimento dos direitos políticos, em conformidade com as legislações nacionais, em favor dos nacionais de um dos Estados-Partes que residem em um país da região da qual não sejam nacionais, incluída a possibilidade de eleger os parlamentares do Mercosul.

O cronograma de trabalho para colocar em prática o Estatuto da Cidadania do Mercosul e todos os objetivos previstos no documento é de dez anos, contados a partir do momento da assinatura, isto é, até o ano de 2021. Como dito em precedência, após a implementação integral deste Plano de Ação, os Estados-Partes podem assinar um protocolo que expressamente introduza o conceito de "Cidadania do Mercosul" no direito primário do Mercosul.

Trata-se, certamente, de um percurso muito diferente daquele realizado no âmbito europeu. No Mercosul emerge a preocupação de criar este Estatuto de modo gradual, segundo uma programação previamente definida, e sempre através da ação dos órgãos "executivos" da integração. Ao invés, os direitos dos cidadãos no âmbito da União Europeia foram em boa parte desenvolvidos pelo Tribunal de Justiça, o qual indicou o percurso a ser seguido a fim de consolidar um estatuto para o cidadão europeu. Além disso, a maioria dos direitos reservados aos cidadãos europeus pelo Tratado de Maastricht não constituía uma novidade, considerando que os mesmos já se encontravam presentes em vários atos comunitários e eram usufruídos pelos indivíduos antes mesmo de 1992. Vice-versa, no Mercosul, os direitos que se referem diretamente aos cidadãos são ainda poucos e, neste contexto, o principal objetivo do Plano de Ação é a atuação progressiva deste Estatuto para, ao final, introduzir o conceito de "Cidadão do Mercosul".

Nesta perspectiva, em ocasião no vigésimo aniversário do Mercosul, o Ministro de Relações Exteriores do Brasil declarou que esta organização se sustenta em três pilares: o econômico-comercial, o social e o "cidadão". Ele afirmou ainda que este último progrediu significativamente nos últimos anos, sinalizando a Decisão que elaborou o Plano de Ação do Estatuto da Cidadania do Mercosul, durante a Presidência pro tempore do Brasil. O objetivo final, segundo o Ministro, é consolidar os direitos já existentes e ampliá-los a fim de que se estabeleça uma "efetiva cidadania mercosulina"15.

Com relação ao âmbito das políticas sociais, pode-se notar que a situação dos imigrantes e dos seus familiares representa um ponto estratégico ligado ao 
debate em torno do Estatuto da Cidadania do Mercosul, ou seja, dos direitos que serão reconhecidos aos cidadão de todos os Estados-Partes. Com tal propósito, deve-se pensar em um núcleo básico de direitos a fim de que a cidadania regional se transforme em um valor construído e consolidado, levando em consideração este âmbito comum. As políticas de igualdade e de não discriminação, nesse sentido, são fundamentais porque refletem a ideia do direito e da cidadania ${ }^{16}$.

Deste modo, a existência de uma cidadania comum a uma pluralidade de indivíduos que pertencem a uma determinada região geopolítica, unida por objetivos e interesses comuns e organizada em uma estrutura institucional internacional, é um ideal que não mais faz parte somente da realidade do processo de integração regional da União Europeia. Unir os povos em favor de uma dimensão social que ultrapasse o aspecto puramente econômico apresenta-se como um dos escopos emergentes dos vários Países reunidos através do vínculo de um tratado internacional de integração. A história, os percursos, a estrutura, os métodos, as dificuldades e os desafios podem, muitas vezes, ser afrontados de diferentes modos por cada organização regional, mas aquilo que vale, no final das contas, é a utilidade que podemos retirar de uma análise positiva das várias experiências.

\section{NOTAS}

1 WOLKMER, Antônio Carlos. Integração e direito comunitário latino-americano. In: PIMENTEL, Luiz Otávio (Org.). Mercosul no cenário internacional: direito e sociedade. Vol. 1. Curitiba: Juruá, 1998, p. 51-52.

2 WOLKMER, Antônio Carlos. 1998, p. 52.

3 Reunião ocorrida em Brasília, Brasil, entre os dias 5 e 6 de dezembro de 2002.

4 Para uma análise completa da cidadania europeia e da liberdade de circulação ver: NASCIMBENE, Bruno; ROSSI DAL POZZO, Francesco. Diritti di cittadinanza e libertà di circolazione nell'Unione europea. Padova: CEDAM, 2012; NASCIMBENE, Bruno, Le droit de la nationalité et le droit des organisations d'intégration régionales. Vers de nouveaux statuts de résidents?, Recueil des Cours de l'Académie de La Haye, t. 367, 2014, p. 296 ss.

5 VARELA, Justo Corti. Evolución de la libre circulación de personas en el Mercosur y su impacto en las políticas migratorias nacionales. In: VÉRTIZ, Juana Goizueta; FERNÁNDEZ, Itziar Gómez; PASCUAL, María Isabel González (Dir.). La libre círculación de personas en los sistemas de integración económica: modelos comparados: Unión Europea, Mercosur y Comunidad Andina. Navarra: Thomson Reuters Aranzadi, 2012, p. 144-145.

6 AGUIRRE, Orlando; MERA, Gabriela; NEJAMKIS, Lucila. Políticas migratorias e integración regional: la libre circulación y los desafíos a la ciudadanía. In: NOVICK, Susana (Dir.). Migraciones y Mercosur: una relación inconclusa. Buenos Aires: Catálogos: 2010, p. 59.

7 SALZMANN, Antonio Cardesa. El contenido jurídico de la libre circulación de personas en el Mercosur: balance y perspectivas. In: VÉRTIZ, Juana Goizueta; FERNÁNDEZ, Itziar Gómez; PASCUAL, María Isabel González (Dir.). La libre círculación de personas en los sistemas de integración económica: modelos comparados: Unión Europea, Mercosur y Comunidad Andina. Navarra: Thomson Reuters Aranzadi, 2012, p. 166. 
8 Discurso do Presidente do Uruguai em 20 de junho de 2005 em Assunción, Paraguai, durante a Cúpula de Chefes de Estado e de Giverno do Mercosul. In: Vázquez: hay que llenar de ciudadanía al Mercosur. Disponível em: http://archivo.presidencia.gub.uy/_web/noticias/2005/06/2005062007. htm. Acessado em 20 de setembro de 2014. Sublinado nosso.

9 Esta Comissão é um órgão que assiste o CMC e o GMC no desenvolvimento das suas funções e tem sede em Montevidéu, Uruguai.

10 O "Cartilha do Cidadão do Mercosul: compilação de normas relacionadas com o cidadão do Mercosul” foi formulado pela Comissão dos Representantes Permanentes do Mercosul e publicada no mês de julho de 2010.

11 Dec. CMC n. 64/10 de 16 de dezembro de 2010 em Foz do Iguaçu, Brasil. O ato não necessita ser incorporado nos ordenamentos jurídicos nacionais pois regula aspectos da organização ou do funcionamento do Mercosul, recaindo em uma das exceções à regra da vigência simultânea.

12 Art. 7: “O Plano de Ação deverá estar integralmente implementado no $30^{\circ}$ aniversário do MERCOSUL. O Estatuto da Cidadania do MERCOSUL poderá ser instrumentalizado por meio da assinatura de um protocolo internacional que incorpore o conceito de "Cidadão do MERCOSUL" $e$ forme parte do Tratado de Assunção."

13 SALZMANN, Antonio Cardesa. 2012, p. 174-175.

14 JUNIOR, Renato G. Flôres. Símbolos e integrações regionais: uma breve introdução com vistas ao Mercosul. Cadernos Adenauer, VIII (2007), n. 1. União Europeia e Mercosul: dois momentos especiais da integração regional. Rio de Janeiro: Fundação Konrad Adenauer, maio 2007, p. 26.

15 Entrevista do Ministro Antônio Patriota ao Jornal Em Questão de 26 de março de 2011. Para Patriota, o objetivo é estabelecer uma efetiva cidadania mercosulina. Disponível em: http://www. itamaraty.gov.br/sala-de-imprensa/discursos-artigos-entrevistas-e-outras-comunicacoes/ministroestado-relacoes-exteriores/para-patriota-o-objetivo-e-estabelecer-uma-efetiva-cidadaniamercosulina-em-questao-secom-pr-26-3-2011. Acessado em 15 de agosto de 2014. O Ministro salienta ainda que os três grandes desafios do Mercosul atualmente: a consolidação da união aduaneira, o plano estratégico de Ação Social e o Estatuto da Cidadania.

16 ABRAMOVICH,Victor. Direitos humanos no marco do processo de integração regional no Mercosul. Revista de la Secretaría del Tribunal Permanente de Revisión. Año 1, 2-2013. p. 358. Recordamos, à título de curiosidade, que a União das Nações Sul-americanas (UNASUL), criada em 2008, se propõe a cria uma "cidadania sul-americana" comum. Cfr. de recente NASCIMBENE, Bruno, 2014, p. 388 ss.

\section{Referências Bibliográficas}

ABRAMOVICH,Victor. Direitos humanos no marco do processo de integração regional no Mercosul. Revista de la Secretaría del Tribunal Permanente de Revisión. Año 1, 2-2013.

AGUIRRE, Orlando; MERA, Gabriela; NEJAMKIS, Lucila. Políticas migratorias e integración regional: la libre circulación y los desafíos a la ciudadanía. In: NOVICK, Susana (Dir.). Migraciones y Mercosur: una relación inconclusa. Buenos Aires: Catálogos: 2010.

Discurso do Presidente do Uruguai em 20 de junho de 2005 em Assunción, Paraguai, durante a Cúpula de Chefes de Estado e de Governo do Mercosul. In: Vázquez: hay que llenar de ciudadanía al Mercosur. Disponível em: http://archivo.presidencia.gub.uy/_ web/noticias/2005/06/2005062007.htm. Acessado em 20 de setembro de 2014. 
Entrevista do Ministro Antônio Patriota ao Jornal Em Questão de 26 de março de 2011. Para Patriota, o objetivo é estabelecer uma efetiva cidadania mercosulina. Disponível em: http://www.itamaraty.gov.br/sala-de-imprensa/discursos-artigos-entrevistas-eoutras-comunicacoes/ministro-estado-relacoes-exteriores/para-patriota-o-objetivoe-estabelecer-uma-efetiva-cidadania-mercosulina-em-questao-secom-pr-26-3-2011. Acessado em 15 de agosto de 2014.

JUNIOR, Renato G. Flôres. Símbolos e integrações regionais: uma breve introdução com vistas ao Mercosul. Cadernos Adenauer, VIII (2007), n. 1. União Europeia e Mercosul: dois momentos especiais da integração regional. Rio de Janeiro: Fundação Konrad Adenauer, maio 2007.

NASCIMBENE, Bruno; ROSSI DAL POZZO, Francesco. Diritti di cittadinanza e libertà di circolazione nell'Unione europea. Padova: CEDAM, 2012.

NASCIMBENE, Bruno, Le droit de la nationalité et le droit des organisations d'intégration régionales. Vers de nouveaux statuts de résidents?, Recueil des Cours de l’Académie de La Haye, t.. 367, 2014.

SALZMANN, Antonio Cardesa. El contenido jurídico de la libre circulación de personas en el Mercosur: balance y perspectivas. In: VÉRTIZ, Juana Goizueta; FERNÁNDEZ, Itziar Gómez; PASCUAL, María Isabel González (Dir.). La libre círculación de personas en los sistemas de integración económica: modelos comparados: Unión Europea, Mercosur y Comunidad Andina. Navarra: Thomson Reuters Aranzadi, 2012.

VARELA, Justo Corti. Evolución de la libre circulación de personas en el Mercosur y su impacto en las políticas migratorias nacionales. In: VÉRTIZ, Juana Goizueta; FERNÁNDEZ, Itziar Gómez; PASCUAL, María Isabel González (Dir.). La libre círculación de personas en los sistemas de integración económica: modelos comparados: Unión Europea, Mercosur y Comunidad Andina. Navarra: Thomson Reuters Aranzadi, 2012.

WOLKMER, Antônio Carlos. Integração e direito comunitário latino-americano. In: PIMENTEL, Luiz Otávio (Org.). Mercosul no cenário internacional: direito e sociedade. Vol. 1. Curitiba: Juruá, 1998. 


\section{Resumo}

O Mercosul tem estimulado a adoção de políticas regionais tendentes à valorização da sua dimensão social, alcançando uma esfera até pouco tempo marginalizada pelo processo de integração. Nesse sentido, o cidadão emerge como o centro de diversas medidas adotadas com o escopo de tutelar seus interesses e direitos individuais e coletivos. A entrada em vigor dos Acordos de Residência em dez países latino-americanos simboliza e, acima de tudo, materializa, os anseios de uma integração vertical, isto é, que parte da sociedade civil como um todo e alcança a esfera institucional do fenômeno regional. O Plano de Ação para a criação do Estatuto da Cidadania do Mercosul insere-se neste novo contexto, pautado por fortes ideais de solidariedade, todavia, parece encontrar diversos obstáculos de caráter político, por parte dos governos nacionais, a fim de efetivamente levar adiante a proposta e atuar medidas concretas que não se consolidam se pairarem apenas no plano das ideias e do discurso.

Palavras-chave: Cidadania. Processo de Integração Regional. Mercosul. Direitos e Prerrogativas. Residência e Migração. 


\title{
THE ACTION PLAN FOR THE CREATION OF THE MERCOSUR CITIZENSHIP STATUTES
}

\begin{abstract}
Mercosur has encouraged the adoption of regional policies aimed at enhancing its social dimension, reaching a sphere that until recently was marginalized by the integration process. In this sense, the citizen emerges as the center of several measures adopted with the scope of protecting his interests and individual and collective rights. The entry into force of the Residency Agreements in ten Latin American countries symbolizes and, above all, materializes the aspirations of a vertical integration, that is, that part of the civil society as a whole and reaches the institutional sphere of the regional phenomenon. The Action Plan for the creation of the Mercosur Citizenship Statute is part of this new context, based on strong ideals of solidarity, however, it seems to find several obstacles of a political nature by the national governments, in order to effectively carry out the proposal and concrete measures that do not consolidate if they only hover on the level of ideas and discourse.
\end{abstract}

Keywords: Citizenship. Regional Integration Process. Mercosur. Rights and Prerogatives. Residence and Migration.

Recebido em abril de 2018. Aprovado em junho de 2018. 